\title{
Tumour necrosis factor- $\alpha(-308)$ gene polymorphism in obstructive sleep apnoea-hypopnoea syndrome
}

\author{
R.L. Riha*, P. Brander*, M. Vennelle*, N. McArdle*, S.M. Kerr”, \\ N.H. Anderson ${ }^{\star}$ and N.J. Douglas*
}

ABSTRACT: Patients with obstructive sleep apnoea-hypopnoea syndrome (OSAHS) have elevated circulating levels of tumour necrosis factor (TNF)- $\alpha$. The hypothesis in this study was that OSAHS might be associated with the TNF- $\alpha$ (-308A) gene polymorphism, which results in increased TNF- $\alpha$ production. This hypothesis was examined in OSAHS patients, their siblings and population controls.

A total of 206 subjects were recruited. All underwent sleep studies and clinical review, and were subsequently classified as having OSAHS or not depending on apnoea-hypopnoea frequency, sex, age and symptoms. All subjects had blood collected and genotyping was performed on DNA extracted from peripheral leukocytes. Some 192 random UK blood donors were used as population controls.

The results demonstrated a significant association for TNF- $\alpha$ (-308A) allele carriage with OSAHS $(O R=1.8 ; 95 \%$ Confidence interval: 1.18-2.75) when compared with population controls. Siblings with OSAHS were significantly more likely to carry the TNF- $\alpha$ (-308A) allele. In addition, 21 pairs of male siblings discordant for carriage of the -308A allele showed a significant level of discordance for the OSAHS phenotype.

In conclusion, this study demonstrates an association of tumour necrosis factor- $\alpha(-308 \mathrm{~A})$ carriage with obstructive sleep apnoea-hypopnoea syndrome, suggesting that inflammation may be implicated in the pathogenesis of this condition.

KEYWORDS: Genetics, obstructive sleep apnoea, tumour necrosis factor- $\alpha$

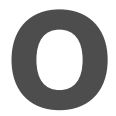
bstructive sleep apnoea-hypopnoea syndrome (OSAHS) is the second most common respiratory condition, affecting $\sim 0.3-4 \%$ of the middle-aged population. It is defined on the basis of symptoms of daytime sleepiness and objective measures of disordered breathing during sleep $[1,2]$. OSAHS has a familial component, independent of obesity [3], and there is increasing evidence that OSAHS is associated with inflammation. Raised levels of Creactive protein, hypercytokinaemia and tumour necrosis factor (TNF)- $\alpha$ have been reported in OSAHS [4-6]. The raised serum TNF- $\alpha$ level is independent of obesity and correlates with systemic blood pressure [5, 7, 8]. Furthermore, TNF- $\alpha$ also promotes sleepiness, the major feature of OSAHS [9].

Increased production of TNF- $\alpha$ both in vitro and in vivo has been reported to be associated with a functional TNF- $\alpha$ gene polymorphism, consisting of a guanine $(\mathrm{G})$ to adenine $(\mathrm{A})$ substitution at position -308 in the promoter region $[10,11]$. It was thus hypothesised that OSAHS might be associated with the TNF- $\alpha$ (-308A) gene polymorphism. This was tested in OSAHS patients, their siblings and population controls.

\section{METHODS}

A case-control study, based on the recruitment of patients with OSAHS and their available siblings, was undertaken between January 1997 and December 2002 at the Scottish Sleep Centre (Edinburgh, UK). A total of 192 random anonymous UK blood donors were used as additional population controls. Approval for the study was obtained from the local research ethics committee (Edinburgh, UK).

\section{Recruitment of subjects}

A total of 557 consecutive patients attending the Scottish Sleep Centre with symptoms of OSAHS and an apnoea-hypopnoea index (AHI) $\geqslant 15$ were asked to participate in the study as index

\section{AFFILIATIONS}

${ }^{*}$ Respiratory Medicine, and

"Public Health Sciences, University of Edinburgh, and

"Genetics Core, Wellcome Trust Clinical Research Facility, Edinburgh, UK.

CORRESPONDENCE

R.L. Riha

Respiratory Medicine Royal Infirmary of Edinburgh

51 Little France Crescent

Edinburgh

EH16 4SA

UK

Fax: 441312421776

E-mail: rlriha@hotmail.com

Received:

November 152004

Accepted after revision:

July 012005

SUPPORT STATEMENT

R.L. Riha was the recipient of an Australian Federation of University Women (AFUW) Fellowship, European Respiratory Society (ERS) Long-Term Training Fellowship and Helen Bearpark Scholarship whilst undertaking this work. P. Brander was the recipient of a scholarship from the Finnish Anti-Tuberculosis Association Foundation.

European Respiratory Journal Print ISSN 0903-1936 Online ISSN 1399-3003 
cases, and were requested to contact their siblings to ask them to complete a sleep questionnaire, take part in a sleep study and provide a blood sample. Out of 312 index subjects willing to participate in the study, 155 had siblings who were also available. Some 44 siblings defaulted on attendance and eight sibling pairs had technically inadequate data collected. In total, 103 sib-pairs (206 subjects) successfully completed the study. All subjects were Caucasian.

\section{Data collection}

After giving written, informed consent, all subjects had their height, weight and neck circumference and blood pressure measured, and were asked to fill out a standard sleep questionnaire (including an Epworth Sleepiness Score (ESS) [12]). Subjects had $20 \mathrm{~mL}$ of blood collected. All siblings had overnight polysomnography (PSG) using standard techniques [13]. Studies were performed in sound-proofed and electrically screened bedrooms at the Edinburgh Sleep Centre (UK).

Sleep was recorded using electroencephalography (EEG), electro-oculography (EOG) and electromyography (EMG), using bipolar signals from silver chloride surface electrodes. EEG was recorded from two scalp sites $(\mathrm{Cz} / \mathrm{Pz})$. Frontal EEG was also recorded using "mixed" channels comprising EEG/ EOG signals ( $\mathrm{Cz} / \mathrm{Fp} 1, \mathrm{Cz} / \mathrm{Fp} 2)$. The EOG was recorded from electrodes placed at sites on the outer canthus of the eye and Fp1 and Fp2. Submental EMG was recorded using two electrodes placed on the belly of the genioglossus. A grounding electrode was placed at Fpz. Electrodes placed on the right and left anterior tibialis recorded leg EMG. All signals were recorded on the Compumedics $\mathrm{W}$-series and R-series systems (Compumedics, Melbourne, Australia).

Index patients had either overnight PSG (87 out of 103) or a home (16 out of 103 cases) study using the limited sleep study system Edentrace (EdenTec Model 3711 Digital Recorder; Nellcor, Eden Prairie, Minnesota, USA), which has been extensively validated against PSG [14, 15]. This device records oronasal airflow using a thermocouple, chest wall movement by electrical impedance, heart rate using an electrocardiogram and finger pulse oximetry; no EEG is recorded.

Sleep studies were analysed by one researcher (R.L. Riha) after blinding of data using standard scoring criteria [14, 16, 17].

\section{Phenotyping}

OSAHS phenotype was defined using AHI and sleepiness, as measured by the ESS. Table 1 shows the AHI cut-off values based on normative data for Caucasian subjects [2, 18, 19]. Each subject's AHI was first scored as either definitely abnormal, indeterminate or definitely normal on the basis of sex and age. Each subject's ESS (out of a total of 24) was then scored as either sleepy (ESS $\geqslant 11$ out of 24 ) or not abnormally sleepy (ESS $<11$ out of 24 ). The ESS cut-offs were based on normative data derived for Caucasian subjects [20, 21].

OSAHS was then classified as being definitely present, indeterminate or definitely absent by the algorithm represented in table 2.

\section{Blood donors}

DNA from UK Caucasian human random control DNA panels (Product No. HRC-1 96 array and No. HRC-2 96 array;

\begin{tabular}{llc}
\hline TABLE 1 & $\begin{array}{l}\text { Classification of apnoea-hypopnoea index (AHI) } \\
\text { according to sex and age }\end{array}$ \\
\cline { 2 - 3 } & \multicolumn{2}{c}{ AHI. $\mathbf{h}^{-1}$} \\
\hline & Male & Female \\
\hline Normal & & \\
$20-40$ yrs & $<10$ & $<10$ \\
$40-60$ yrs & $<15$ & $<10$ \\
$>60$ yrs & $<20$ & $<15$ \\
Indeterminate & & $10-15$ \\
$20-40$ yrs & $10-15$ & $10-15$ \\
$40-60$ yrs & $15-20$ & $15-20$ \\
$>60$ yrs & $20-30$ & $>15$ \\
Abnormal & & $>15$ \\
$20-40$ yrs & $>15$ & $>20$ \\
$40-60$ yrs & $>20$ & \\
$>60$ yrs & $>30$ &
\end{tabular}

\begin{tabular}{|c|c|c|}
\hline TABLE 2 & $\begin{array}{l}\text { Presence or absence of o } \\
\text { apnoea-hypopnoea syndr } \\
\text { phenotype using scores } \\
\text { hypopnoea index (AHI) an }\end{array}$ & $\begin{array}{l}\text { uctive sleep } \\
\text { (OSAHS) } \\
\text { d for apnoea- } \\
\text { eepiness }\end{array}$ \\
\hline Score for AHI & Score for sleepiness & OSAHS phenotype \\
\hline Abnormal & Abnormal & OSAHS \\
\hline Abnormal & Normal & Indeterminate \\
\hline Indeterminate & Abnormal & OSAHS \\
\hline Indeterminate & Normal & No OSAHS \\
\hline Normal & Abnormal & No OSAHS \\
\hline Normal & Normal & No OSAHS \\
\hline
\end{tabular}

European Collection of Cell Cultures, http://www.ecacc. org.uk) was used as a second set of controls. All donors gave written informed consent for their blood to be used for research purposes.

\section{Allelic discrimination analysis}

DNA for recruited subjects was extracted using the Wizard® R Genomic DNA Purification Kit (TM050; Promega, Southampton, UK) or the Nucleon Extraction and Purification Protocol (for extraction of DNA from $10 \mathrm{~mL}$ of whole blood; Nucleon BACC3 RPN 8512; Amersham plc, Little Chalfont, UK).

The TaqMan system was used to study the -308 (A-G) single nucleotide polymorphism (SNP). Assay-by-Design ${ }^{\circledR}$ (Applied Biosystems, Foster City, CA, USA) was used to design the probe and primers.

Each $10 \mu \mathrm{L}$ of PCR contained $10 \mu \mathrm{g}$ of genomic DNA, $900 \mu \mathrm{M}$ primers, $250 \mu \mathrm{M}$ probes and $2.5 \mu \mathrm{L}$ of TaqMan Universal PCR master mix (Applied Biosystems). The solution was pipetted into each well of a 96- or 384-well plate using an automated liquid handling robot. 
Amplification was performed using the Peltier Thermal Cycler (PTC-225 DNA tetrad PCR machine; MJ Research, Waltham, MA, USA). Fluorescence in each well was measured before and after PCR using an ABI PRISM 7900HT Sequence Detector (Applied Biosystems) and reproduced as scatter diagrams. Alleles were read and classified on the plots by two readers independently blinded to subject status.

\section{Statistical analysis}

Between-group comparisons were performed using the Chisquared test and unpaired and paired t-tests. A logistic regression model using generalised estimating equations was used to test the association of OSAHS with TNF- $\alpha$ carriage on an allele-counting basis (assuming Hardy-Weinberg equilibrium and a multiplicative risk model) [22]. The significance of frequency differences of OSAHS between genotypediscordant sibling pairs was estimated using one sibling pair from each family by McNemar's test of symmetry. Association and linkage analysis of OSAHS with the TNF- $\alpha$ (-308) SNP was performed using formulae in the SIBASSOC programme [23]. SIBASSOC performs a Chi-squared test using the most genotypically distinct unaffected sibling as a control for each case. The FBAT [24] programme was used to examine the association of quantitative traits with genotype. Power was determined using the formulae described by MACHIN et al. [25] for case-controlled studies comparing two proportions and using the odds ratio (OR). The Hardy-Weinberg equilibrium was tested using the following formula:

$$
1=\mathrm{p}^{2}+2 \mathrm{pq}+\mathrm{q}^{2}
$$

for allelic distribution in the population, and the frequencies of minor and major alleles were compared with published frequencies.

All p-values are for two-tailed tests and considered to be significant at the $\alpha=0.05$ level.

\section{RESULTS}

Sixty-three subjects had no OSAHS and 40 were classed as intermediate for OSAHS by criteria determined a priori (tables 1 and 2). Population characteristics for the study subjects with definite OSAHS and definitely no OSAHS are presented (table 3). Subjects classified as indeterminate for OSAHS $(n=40)$ were not included in subsequent analyses.

Genotyping results for the -308 (A-G) SNP for TNF- $\alpha$ were available for 190 UK blood donor controls (99\%) and 200 out of the 206 study subjects (97\%). Of the blood donor controls, 95 $(50 \%)$ were male and the mean \pm SD age was $38 \pm 8$ yrs.

The distribution of allelic frequencies and genotypes was significantly different between subjects with a definite diagnosis of OSAHS and UK population controls (table 4). Allele distribution in the control group ( $n=190$ blood donors) was in Hardy-Weinberg equilibrium.

Logistic regression showed a significant association for TNF- $\alpha$ $(-308 \mathrm{~A})$ allele carriage with OSAHS (OR (95\% confidence interval) $1.82(1.18-2.75) ; \mathrm{p}=0.006)$.

Analysis of quantitative traits (AHI and body mass index (BMI)) showed no association independently with a diagnosis

\begin{tabular}{|c|c|c|c|}
\hline & No OSAHS & Definite OSAHS & $\mathrm{p}$-value \\
\hline Subjects $n$ & 63 & 103 & \\
\hline Sex ratio M:F & $33: 30$ & $83: 20$ & $<0.0001$ \\
\hline Age yrs & $51 \pm 10$ & $52 \pm 9$ & 0.6 \\
\hline$B M I \mathbf{k g} \cdot \mathbf{m}^{-2}$ & $27 \pm 5$ & $30 \pm 6$ & $<0.0001$ \\
\hline Neck circumference $\mathrm{cm}$ & $37 \pm 4$ & $41 \pm 4$ & $<0.0001$ \\
\hline SBP $\mathrm{mmHg}$ & $130 \pm 17$ & $138 \pm 18$ & 0.007 \\
\hline DBP $\mathrm{mmHg}$ & $82 \pm 12$ & $84 \pm 12$ & 0.6 \\
\hline Sleep efficiency ${ }^{\#}$ & $76 \pm 12$ & $73 \pm 15$ & 0.1 \\
\hline REM time min & $70 \pm 24$ & $64 \pm 30$ & 0.2 \\
\hline NREM time min & $287 \pm 47$ & $275 \pm 62$ & 0.2 \\
\hline $\mathrm{Sa}, \mathrm{O}_{2} \%$ awake & $97 \pm 2$ & $96 \pm 2$ & 0.07 \\
\hline Lowest $\mathrm{Sp}, \mathrm{O}_{2} \%$ & $90 \pm 7$ & $83 \pm 10$ & $<0.0001$ \\
\hline
\end{tabular}

OSAHS: obstructive sleep apnoea-hypopnoea syndrome; M: male; F: female: BMI: body mass index; SBP: systolic blood pressure; DBP: diastolic blood pressure; REM: rapid eye movement sleep; NREM: nonrapid eye movement sleep; $\mathrm{Sa}, \mathrm{O}_{2}$ : arterial oxygen saturation awake; $\mathrm{Sp}, \mathrm{O}_{2}$ : arterial oxygen saturation asleep. ${ }^{\#}$ : as a percentage of the total time spent asleep divided by the time of the study.

\begin{tabular}{|c|c|c|c|}
\hline \multirow[t]{2}{*}{ TABLE 4} & \multicolumn{3}{|c|}{$\begin{array}{l}\text { Allelic and genotype frequencies for tumour } \\
\text { necrosis factor- } \alpha(-308) \text { A-G polymorphism in } \\
\text { subjects with definite obstructive sleep apnoea- } \\
\text { hypopnoea syndrome (OSAHS) versus } \\
\text { population controls }\end{array}$} \\
\hline & Controls & Definite OSAHS & p-value \\
\hline Subjects $n$ & 190 & 103 & \\
\hline $\mathbf{G} / \mathbf{G}$ & $130(69)$ & $52(51)$ & 0.01 \\
\hline$A / G$ & $52(27)$ & $44(43)$ & \\
\hline$A / A$ & $8(4)$ & $7(7)$ & \\
\hline Alleles $n$ & 380 & 206 & \\
\hline G & $312(82)$ & $148(72)$ & 0.004 \\
\hline$A$ & $68(18)$ & $58(28)$ & \\
\hline
\end{tabular}

Data are presented as n (\%), unless otherwise stated.

of OSAHS or with genotype ( $\mathrm{p}=0.4$ and $\mathrm{p}=0.5$, respectively). This was based on 35 informative sibling groups.

Forty-five pairs of siblings (males and females) were discordant for the diagnosis of OSAHS (the remainder was concordant for the diagnosis or one of the siblings had intermediate phenotype). There was a significantly higher prevalence of the $-308 \mathrm{~A}$ allele in the siblings with OSAHS $(p=0.04)$ using SIBASSOC. Anthropometric and sleep variables in this group are shown in table 5.

Several papers have suggested that there may be sexual dimorphism in innate immune responses, including the secretion of TNF- $\alpha$ [26-28]. Logistic regression analysis corrected for sex still showed significant association of the $-308 \mathrm{~A}$ allele with OSAHS (1.64 (1.06-2.55); $p=0.023)$. Further analysis was undertaken using McNemar's test in 21 pairs of male siblings 


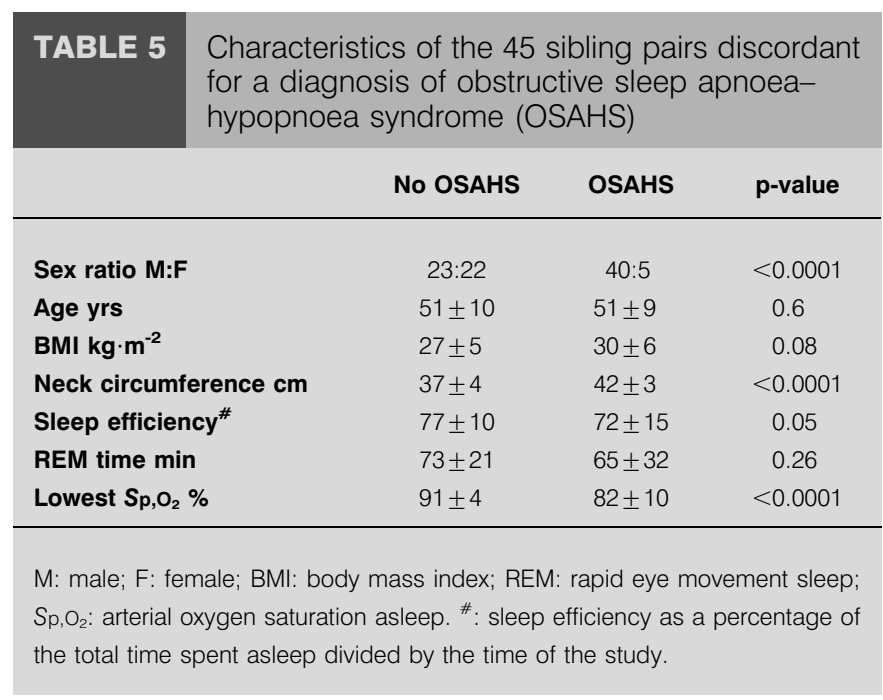

discordant for carriage of the -308A allele. Fifteen subjects in this group who were A-allele positive had OSAHS whilst their siblings did not $(p=0.001)$. There was no significant difference between the $21 \mathrm{sib}$-pairs with and without the $-308 \mathrm{~A}$ allele with regard to BMI $\left(28 \pm 3\right.$ versus $\left.28 \pm 5 \mathrm{~kg} \cdot \mathrm{m}^{-2}\right)$ or age $(50 \pm 9$ versus $51 \pm 9$ yrs). Female sib-pairs in the study were either concordant for OSAHS or one of the pair had an intermediate phenotype, precluding similar analysis.

\section{DISCUSSION}

In this study, the TNF- $\alpha$ (-308A) allele was significantly associated with a diagnosis of OSAHS, both in cases versus random population controls and in siblings. The marked association between the TNF- $\alpha(-308 \mathrm{~A})$ allele and OSAHS in the male sib-pairs discordant for OSAHS strongly suggests that this relationship is significant. However, this allele is not required for the development of OSAHS, as its prevalence was $28 \%$ in the OSAHS group overall compared with $18 \%$ in population controls.

Inflammation in OSAHS is common and includes elevated levels of circulating pro-inflammatory cytokines. TNF- $\alpha$ and interleukin (IL)- 6 are elevated in OSAHS, independently of obesity, and the circadian rhythm of TNF- $\alpha$ secretion is disrupted [29]. Additionally, other mediators of inflammation are also elevated, including intracellular adhesion molecule-1 and C-reactive protein [30]. TNF- $\alpha, \mathrm{C}$-reactive protein and IL-6 appear to produce their harmful effects by inducing endothelial dysfunction. TNF- $\alpha$ damages endothelial cells, causes apoptosis of these cells and triggers procoagulant activity and fibrin deposition. TNF- $\alpha$ also enhances the production of reactive oxygen species, including inducible nitric oxide, and decreases myocardial contractility in a dose-dependent fashion [31].

Sleep disruption in OSAHS may be one factor driving the increased susceptibility to cardiovascular diseases in this condition. A genetic propensity towards increased TNF- $\alpha$ production may further exacerbate these effects. The driving forces leading to elevations of pro-inflammatory cytokines in OSAHS may be related to increased activity of both branches of the autonomic nervous system, intermittent hypoxia, localised inflammation in the oropharynx leading to increased cytokine induction, and increased visceral adiposity [30].

In the present study, an independent association of the TNF- $\alpha$ (-308A) SNP with the diagnosis of OSAHS has been demonstrated. This suggests a disease-promoting role, manifest as increased susceptibility to symptoms (somnolence and fatigue) and exacerbation of upper airways inflammation. A further extension of this work would include measurement of serum levels of circulating TNF- $\alpha$, serum-soluble TNF receptor p55 and serum-soluble receptor p75 in all subjects, which the current study design precluded.

The strengths of this study include the sibling pair design with additional population controls, the scoring of all records blind to case or allele status and the a priori agreed classification of case status. The study has several potential limitations. AHI was measured on a single night only, when it may vary from night to night [32]; however, a 1-night study is the standard and only realistic way of assessing sleep-disordered breathing in volunteer (or patient) studies. All study participants were investigated in the same laboratory, using the same standardised techniques for setting up, recording and scoring events. There was a high intra- and inter-rater reproducibility for analysing results, which were performed blind to subject status. The a priori use of an indeterminate score reduced misclassification by making a wide distinction between those with definite sleep apnoea and those definitely without it. The ESS allowed for appraisal of somnolence in daily life situations, which more objective tests may not [12]. It is the simplest, most practical and most widely validated and utilised test for general clinical and research use. Furthermore, sleepiness is the major presenting symptom of OSAHS [33].

Although population stratification is a possible explanation for the observed association between OSAHS and TNF- $\alpha$, a number of factors reduce the likelihood of this. Genotype frequencies for the non-OSAHS group were in HardyWeinberg equilibrium, mitigating against genotyping or significant population stratification errors. Following PRITCHARD and ROSENBERG [34], who argued for the use of unlinked genetic markers to detect population stratification in association studies, two polymorphisms (serotonin receptor 2A T102C and growth hormone receptor $+561 \mathrm{G} / \mathrm{T})$, not known to be in linkage disequilibrium with the TNF gene, were examined for association with OSAHS. Genotypic distributions in the entire group were in Hardy-Weinberg equilibrium and no associations with OSAHS were detected. However, the overall number of markers available was insufficient to carry out a formal test for population stratification. Numerous studies have also looked at whether stratification really is a major issue in epidemiological studies and found the error rates to be extremely small $[35,36]$.

TNF- $\alpha$ allele frequencies for the normal subjects in this study were not significantly different compared with published UK data for Caucasians, excluding bias based on ethnicity [37]. The power of the study was also adequate to determine a difference in allelic frequency (two-group continuity corrected Chisquared test of equal proportions showed power of $99 \%$ at $\alpha=0.05$ level) for the analysis between subjects with OSAHS 
and blood donor controls. Although the OSAHS status of the latter group was unknown, this would tend to dilute the reported difference (by inclusion of OSAHS cases as normals) rather than strengthen it. Furthermore, blood donors in the UK are screened to be in good health and the taking of most medicines prohibits donation. Finally, lack of an independent association of genotype with quantitative traits for OSAHS using FBAT may be a reflection of low power in this population with respect to this statistical method per se.

TNF- $\alpha$ (-308A) is in linkage disequilibrium with human leukocyte antigen (HLA) class I and II alleles, the class III region which encodes several components of the complement system and the major histocompatibility class IV cluster, which includes lymphotoxin- $\alpha$ (one of five microsatellites within the TNF locus) and lymphotoxin- $\beta$ [38]. The association of TNF- $\alpha$ (-308A) with OSAHS may, therefore, be due to the direct influence of the SNP in question and/or due to linkage disequilibrium with other polymorphisms within the TNF- $\alpha$ gene or other genes within the HLA system.

In conclusion, this is the first known study to examine the tumour necrosis factor- $\alpha-308$ (A-G) single nucleotide polymorphism in subjects with obstructive sleep apnoeahypopnoea syndrome. The increased prevalence of the $-308 \mathrm{~A}$ allele in subjects with this disease lends support to the argument that it is associated with inflammation. Further research is needed to explore the utility of pro-inflammatory cytokine gene polymorphisms in obstructive sleep apnoeahypopnoea syndrome for risk stratification, thereby paving the way for potential therapeutic strategies, such as tumour necrosis factor- $\alpha$ monoclonal antibodies

\section{ACKNOWLEDGMENTS}

Helpful assistance with this study was provided by the staff of the Dept of Sleep Medicine, the Genetics Core Wellcome Trust Clinical Research Facility (both Edinburgh, UK) and K. Matthews (statistics).

\section{REFERENCES}

1 Stradling JR, Crosby JH. Predictors and prevalence of obstructive sleep apnoea and snoring in 1001 middle aged men. Thorax 1991; 46: 85-90.

2 Young T, Palta M, Dempsey J, Skatrud J, et al. The occurrence of sleep-disordered breathing among middleaged adults. N Engl J Med 1993; 328: 230-235.

3 Mathur R, Douglas NJ. Family studies in patients with the sleep apnea-hypopnoea syndrome. Ann Intern Med 1995; 122: $174-178$.

4 Shamsuzzaman AS, Winnicki M, Lanfranchi $\mathrm{P}$, et al. Elevated C-reactive protein in patients with obstructive sleep apnea. Circulation 2002; 105: 2462-2464.

5 Vgontzas AN, Papanicolaou DA, Bixler EO, et al. Sleep apnea and daytime sleepiness and fatigue: relation to visceral obesity, insulin resistance, and hypercytokinemia. J Clin Endocrinol Metab 2000; 85: 1151-1158.

6 Liu H, Liu J, Xiong S, et al. The change of interleukin-6 and tumor necrosis factor in patients with obstructive sleep apnea syndrome. J Tongji Med Univ 2000; 20: 200-202.

7 Bautista LE, Vera LM, Arenas IA, Gamarra G. Independent association between inflammatory markers (C-reactive protein, interleukin-6, and TNF- $\alpha$ ) and essential hypertension. J Hum Hypertens 2005; 2: 149-154.

8 Demirbas B, Guler S, Cakir B, et al. Plasma tumour necrosis factor- $\alpha$ levels and insulin resistance in nondiabetic hypertensive subjects. Horm Res 2002; 58: 283-286.

9 Opp MR, Toth LA. Neural-immune interactions in the regulation of sleep. Front Biosci 2003; 8: d768-d779.

10 Louis E, Franchimont D, Piron A, et al. Tumour necrosis factor (TNF) gene polymorphism influences TNF- $\alpha$ production in lipopolysaccharide (LPS)-stimulated whole blood cell culture in healthy humans. Clin Exp Immunol 1998; 113: 401-406.

11 Kroeger KM, Steer JH, Joyce DA, et al. Effects of stimulus and cell type on the expression of the -308 tumour necrosis factor promoter polymorphism. Cytokine 2000; 12: 110-119.

12 Johns MW. Reliability and factor analysis of the Epworth Sleepiness Scale. Sleep 1992; 15: 376-381.

13 Cheshire K, Engleman H, Deary I, et al. Factors impairing daytime performance in patients with sleep apnea/ hypopnea syndrome. Arch Intern Med 1992; 152: 538-541.

14 Whittle AT, Finch SP, Mortimore IL, et al. Use of home sleep studies for diagnosis of the sleep apnoea/hypopnoea syndrome. Thorax 1997; 52: 1068-1073.

15 Parra O, Garcia-Esclasans N, Montserrat JM, et al. Should patients with sleep apnoea/hypopnoea syndrome be diagnosed and managed on the basis of home sleep studies? Eur Respir J 1997; 8: 1720-1724.

16 Rechtschaffen A, Kales S. A manual of Standardised Terminology, Techniques and Scoring System for Sleep Stages of Human Subjects. Bethesda, MD, National Institutes of Health, 1968.

17 Sleep-related breathing disorders in adults: recommendations for syndrome definition and measurement techniques in clinical research. The Report of an American Academy of Sleep Medicine Task Force. Sleep 1999; 22: 667-689.

18 Duran J, Esnaola S, Rubio R, Iztueta A. Obstructive sleep apnea-hypopnea and related clinical features in a population-based sample of subjects aged 30 to $70 \mathrm{yr}$. Am J Respir Crit Care Med 2001; 163: 685-689.

19 Bixler EO, Vgontzas AN, Lin HM, et al. Prevalence of sleepdisordered breathing in women: effects of gender. Am J Respir Crit Care Med 2001; 163: 608-613.

20 Maycock G. Sleepiness and driving: the experience of U.K. car drivers. Accid Anal Prev 1997; 29: 453-462.

21 Parkes JD, Chen SY, Clift SJ, et al. The clinical diagnosis of the narcoleptic syndrome. J Sleep Res 1998; 7: 41-52.

22 Carey VJC. Implementation of GEE for S (92/8/7). Boston, Harvard University, 1992.

23 Curtis D. Use of siblings as controls in case-control association studies. Ann Hum Genet 1997; 61: 319-333.

24 Laird N, Horvath $\mathrm{S}, \mathrm{Xu}$ X. Implementing a unified approach to family based tests of association. Genet Epidemiol 2000; 19: 531-544.

25 Machin D, Campbell MJ, Fayers PM, Pinol APY. Sample Size Tables for Clinical Studies. 2nd Edn. Oxford, Blackwell Science Ltd, 1997.

26 Bouman A, Schipper M, Heineman MJ, et al. Gender difference in the non-specific and specific immune response in humans. Am J Reprod Immunol 2004; 52: 19-26. 
27 Moxley G, Stern AG, Carlson P, et al. Premenopausal sexual dimorphism in lipopolysaccharide-stimulated production and secretion of tumor necrosis factor. J Rheumatol 2004; 31: 686-694.

28 Moxley G, Posthuma D, Carlson P, et al. Sexual dimorphism in innate immunity. Arthritis Rheum 2002; 46: 250-258.

29 Entzian P, Linnemann K, Schlaak M, et al. Obstructive sleep apnea syndrome and circadian rhythms of hormones and cytokines. Am J Respir Crit Care Med 1996; 153: 1080-1086.

30 Mills PJ, Dimsdale JE. Sleep apnea: a model for studying cytokines, sleep, and sleep disruption. Brain Behav Immu 2004; 18: 298-303.

31 Das UN. Is obesity an inflammatory condition? Nutrition 2001; 17: 953-966.

32 Bittencourt LR, Suchecki D, Tufik S, et al. The variability of the apnoea-hypopnoea index. J Sleep Res 2001; 10: 245-251.

33 Whyte KF, Allen MB, Jeffrey AA, et al. Clinical features of the sleep apnoea/hypopnoea syndrome. Q J Med 1989; 72: 659-666.
34 Pritchard JK, Rosenberg NA. Use of unlinked genetic markers to detect population stratification in association studies. Am J Hum Genet 1999; 65: 220-228.

35 Ardlie KG, Lunetta KL, Seielstad M. Testing for population subdivision and association in four case-control studies. Am J Hum Genet 2002; 71: 304-311.

36 Khlat M, Cazes MH, Genin E, Guiguet M. Robustness of case-control studies of genetic factors to population stratification: magnitude of bias and type I error. Cancer Epidemiol Biomarkers Prev 2004; 13: 1660-1664.

37 Reynard MP, Turner D, Navarrete CV. Allele frequencies of polymorphisms of the tumour necrosis factor-alpha, interleukin-10, interferon-gamma and interleukin-2 genes in a North European Caucasoid group from the UK. Eur J Immunogenet 2000; 27: 241-249.

38 Ruuls SR, Sedgwick JD. Unlinking tumor necrosis factor biology from the major histocompatibility complex: lessons from human genetics and animal models. Am J Hum Genet 1999; 65: 294-301. 